\title{
O COMPARTILHAMENTO DO CONHECIMENTO EM INCUBADORAS DE EMPRESAS: O ESTADO DA ARTE A PARTIR DE UMA ANÁLISE BIBLIOMÉTRICA
}

\section{KNOWLEDGE SHARING IN BUSINESS INCUBATORS: THE STATE OF ART FROM A BIBLIOMETRIC ANALYSIS}

\author{
Bruna Hernandes Scarabellia \\ Rejane Sartorib \\ Arthur Gualberto Bacelar da Cruz Urpiac
}

\begin{abstract}
RESUMO
Introdução: O compartilhamento do conhecimento é considerado o mais importante processo da Gestão do Conhecimento, contribuindo para o desenvolvimento de vantagens competitivas. Nas incubadoras de empresas não é diferente, pois as empresas incubadas carecem de recursos do conhecimento para seu desenvolvimento, que são possibilitados mediante ao compartilhamento do conhecimento. Objetivo: Evidenciar o estado da arte em publicações que relacionem o compartilhamento do conhecimento e incubadoras de empresas de base tecnológica. Metodologia: Análise bibliométrica baseada no método Knowledge Development Process-Constructivist (Proknow-C), efetuada nos bancos de dados Emerald, Scopus e ScienceDirect, sem recorte temporal. Resultados: Os artigos que relacionam os temas compartilhamento do conhecimento e incubadoras de empresas de base tecnológica começaram a ser publicados em 2009, com uma tímida tendência de crescimento nos anos seguintes. Em conformidade com a constatação de se tratar de uma área ainda incipiente em termos de publicações científicas, os artigos encontrados não apresentam um número elevado de citações. Não foi possível evidenciar os periódicos com maior número de publicações na temática pesquisada. As palavras-chave encontradas apresentam aderência com aquelas utilizadas nas buscas nas bases de dados. Conclusões: Partindo do objetivo geral deste estudo, este artigo evidencia o estado da arte dos temas relacionados. Foram selecionados nove estudos para compor o portfólio bibliográfico. A análise do
\end{abstract}

\footnotetext{
a Mestranda do Programa de Pós-Graduação em Gestão do Conhecimento nas Organizações da Universidade Cesumar (UniCesumar).E-mail: scarabellibruna@gmail.com

b Doutora em Engenharia e Gestão do Conhecimento pela Universidade Federal de Santa Catarina (UFSC). Docente do Programa de Pós-Graduação em Gestão do Conhecimento nas Organizações da Universidade Cesumar (UniCesumar). Pesquisadora do Instituto Cesumar de Ciência e Tecnologia (ICETI). E-mail: rejane.sartori@unicesumar.edu.br.

c Doutor em Economia pelo Programa de Pós-Graduação em Economia da Universidade Federal do Rio de Janeiro (PPGE-UFRJ). Docente do Programa de Pós-Graduação em Gestão do Conhecimento nas Organizações da Universidade Cesumar (UniCesumar). Pesquisadora do Instituto Cesumar de Ciência e Tecnologia (ICETI). E-mail: arthur.urpia@unicesumar.edu.br.
} 
conteúdo do portfólio encontrado apresenta-se como sugestão de estudo futuro.

Descritores: Gestão do Conhecimento. Compartilhamento do conhecimento. Análise bibliométrica.

\section{INTRODUÇÃO}

O conhecimento é considerado pela sociedade moderna O mais importante ativo que uma organização possui (SCARABELLI; SARTORI; MENEGASSI, 2019). Isso se justifica pela constatação de que seu uso e aplicação constituem a força motriz para a competitividade das corporações, já que pela sua própria natureza favorece o surgimento de inovações. Assim, gerenciar o conhecimento passou a ser percebido como uma atividade essencial no contexto organizacional.

Nesse sentido, a Gestão do Conhecimento é uma abordagem que busca garantir o uso efetivo do conhecimento nas organizações. Pode ser definida como um processo contínuo que possui etapas voltadas para adquirir, armazenar, disseminar, compartilhar e aplicar o conhecimento (CEN, 2004; YOUNG, 2020). O intuito é obter a plena utilização da base de conhecimento da organização, juntamente com o potencial de competências individuais, pensamentos, inovações e ideias, para criar uma organização mais eficaz e eficiente (DALKIR, 2017).

Para que o conhecimento se torne uma verdadeira fonte de vantagens competitivas sustentáveis, é crucial que seja compartilhado no ambiente organizacional. O compartilhamento do conhecimento propicia a partilha de saberes e o aprimoramento de experiências e, em razão disso, é considerado por diversos autores como a etapa mais importante do processo da Gestão do Conhecimento (LIAO; FEl; CHEN, 2007; VELMURUGAN; KOGILAH; DEVINAGA, 2010).

O compartilhamento do conhecimento é definido como uma troca social de recursos intelectuais, podendo ocorrer entre duas ou mais pessoas (CYR; CHOO, 2010; NAVIMIPOUR; CHARBAND, 2016). Dentre os benefícios do compartilhamento do conhecimento, pode-se mencionar o auxílio para superar 
as adversidades e replicação de erros (CYR; CHOO, 2010; YANG, 2007), além de possibilitar o desenvolvimento dos envolvidos por meio da cooperação (JIAN; WANG, 2013; FAROOQ, 2018).

Do mesmo modo que o compartilhamento do conhecimento, a inovação é fundamental para o crescimento sustentado e a prosperidade das organizações. Trata-se de um caminho para a obtenção de vantagens competitivas. Os ganhos propiciados pela inovação são estímulos cruciais para a implementação de produtos e/ou processos novos ou substancialmente aprimorados pela empresa (KÜHL; DA CUNHA, 2013).

Implementar inovações é um desafio que demanda estudo, tempo e recursos (KÜHL; DA CUNHA, 2013), e, em seu percurso, ambientes que contribuam com a promoção do processo de inovação tornam-se cruciais. Dentre esses ambientes destacam-se as incubadoras de empresas, que são espaços disponibilizados para as unidades de negócios com o intuito de auxiliar o seu desenvolvimento. Portanto, incubadoras de empresas são ambientes propícios para o desenvolvimento de ideias inovadoras, que ocorre por meio de suporte gerencial (ANPROTEC, 2019). Para tal, devem interagir com diversos outros organismos, tais como: governo, prefeituras, entidades, agentes de fomento, entre outros (RAUPP; BEUREN, 2006; PIETROVSKI et al., 2010). Além disso, faz-se necessário que as incubadoras propiciem um ambiente favorável ao compartilhamento do conhecimento, pois as empresas incubadas carecem de recursos intangíveis (MIRANDA; BORGES, 2019), principalmente para seu desenvolvimento e crescimento (ZHAO; ZHANG; WU, 2017).

Assim sendo, diante da importância do compartilhamento do conhecimento para as empresas incubadas, bem como da necessidade de conhecer estudos realizados com essas temáticas, esta pesquisa teve como questão norteadora: quais as características das publicações científicas que relacionam compartilhamento do conhecimento e incubadoras de empresas?

Para responder a essa questão, esta pesquisa tem como objetivo evidenciar o estado da arte em publicações que relacionem o compartilhamento do conhecimento e incubadoras de empresas de base tecnológica. Para tanto, está estruturado em cinco seções. Após esta seção introdutória, a seção 
seguinte contém os elementos teóricos que embasam a pesquisa. Na terceira seção relata-se a metodologia empregada e na quarta são apresentados os resultados obtidos, seguidos de discussão. Por fim, na quinta seção são expostas as conclusões, seguidas das referências.

\section{BASE TEÓRICA}

Esta seção aborda os conceitos relacionados a Gestão do Conhecimento e, mais especificamente, ao compartilhamento do conhecimento, assim como sobre incubadoras de empresas, procurando demonstrar a relevância desses temas.

\subsection{Gestão do Conhecimento e Compartilhamento do ConHecimento}

Nos dias atuais tem se observada a importância do conhecimento para as corporações, visto que sua aplicação possibilita o desenvolvimento e aprimoramento de produtos e serviços. O conhecimento possui algumas peculiaridades: diferente dos ativos tangíveis, seu uso não o consome; transferilo não resulta em perdê-lo; e apesar de abundante, a capacidade de usá-lo é escassa (DALKIR, 2017).

O conhecimento se tornou vital para que as organizações possam criar e sustentar vantagens competitivas, além de possibilitar a inovação. Assim, para auxiliar no melhor tratamento do conhecimento nas organizações, é essencial gerenciá-lo. Nesse sentido, a Gestão do Conhecimento é um processo que busca otimizar o uso desse recurso intangível; é vista como um sistema que cria rotinas para que o conhecimento seja compartilhado entre as pessoas em diferentes níveis e ambientes (DALKIR, 2017).

A Gestão do Conhecimento traz importantes benefícios para as organizações, tais como: contribui para a transformação de informação em conhecimento (MACHADO; SILVA; BORTOLOZZI, 2018); auxilia no aproveitamento e alocação do conhecimento disponível nas organizações (DOROW; CALLE; RADOS, 2015); propicia a melhora na produção e em postos de trabalho, assim como favorece a qualificação dos trabalhadores (PICININ; 
KOVALESKI; RAIMUNDI, 2010).

A Comissão Europeia de Normalização (CEN), por meio de seu guia intitulado "European guide to good practice in Knowledge Management", define Gestão do Conhecimento como um processo cíclico, que visa ao melhor uso do conhecimento nas organizações por meio de atividades que objetivam adquirir, armazenar, disseminar, compartilhar e aplicar o conhecimento (CEN, 2004). O compartilhamento do conhecimento é considerado por alguns autores como a etapa mais importante do processo da Gestão do Conhecimento (STYHRE et al., 2008; NAIM; LENKLA, 2016; LIAO; FEI; CHEN, 2007) e pode ser definido como uma parceria entre indivíduos, envolvendo diferentes trocas, tais como know-how, processos e experiências (SMALIUKIENÉ et al., 2017). Trata-se de um fenômeno natural e inerente ao ser humano, que ocorre de forma automática, podendo ser individual ou em grupo (FAROOQ, 2018).

O compartilhamento do conhecimento traz importantes benefícios para as organizações, uma vez que possibilita aos colaboradores acesso aos conhecimentos de que necessitam e favorece a utilização de experiências passadas para superar possíveis dificuldades, o que evita a repetição de erros (CYR; CHOO, 2010). Desta forma, verifica-se que o compartilhamento do conhecimento contribui para a competitividade da organização, pois está ligado à sua capacidade de otimizar a reutilização do conhecimento (TONET; PAZ, 2006). Assim, as empresas que promovem interações para compartilhar conhecimento são mais propensas a possuir melhor desempenho quando comparadas a empresas que não se atentam a isso (FAORO; OLIVEIRA, 2014).

Diversos são os fatores que influenciam no compartilhamento do conhecimento, tais como: cultura e estrutura organizacional, sistemas de recompensas, motivação, confiança interpessoal, suporte de gestão e uso de tecnologias da informação e comunicação (FAROOQ, 2018; RIEGE, 2005). Portanto, as empresas que desejam inovar devem estar atentas aos fatores que podem coibir o compartilhamento do conhecimento (ALCARÁ et al., 2009).

Assim como o compartilhamento do conhecimento, a inovação é fundamental para a obtenção de vantagens competitivas, porém, implementá-la é um desafio para as organizações, demandando estudo, tempo e recursos 
(KÜHL; DA CUNHA, 2013). Nesse sentido, diversos ambientes podem favorecer o processo de inovação e, dentre eles, destacam-se as incubadoras de empresas de base tecnológica. Diante da importância desse tipo de incubadora para a inovação, bem como por se tratar do foco deste estudo, na sequência apresenta-se uma breve explanação sobre esse ambiente.

\subsection{INCUBADORAS DE EMPRESAS}

A competitividade dos mercados apresenta-se como uma dificuldade para as pequenas empresas, as quais possuem relevância para a economia nacional (SCARABELLI; SARTORI; MENEGASSI, 2019). Assim, oferecer suporte a esse tipo de empresa se torna essencial em uma economia em constantes transformações.

Nesse sentido, as incubadoras de empresas são importantes mecanismos de apoio para as pequenas empresas, fomentando a sobrevivência e o desenvolvimento de novos empreendimentos (ANTUNES et al., 2019). Para a International Business Incubation Association (INBIA), as incubadoras de empresas são locais de apoio que oferecem programas de orientação, educação, formação e oportunidades de aprendizagem informal, além de hospedar eventos que fornecem oportunidades de aprendizagem para as empresas e a comunidade local (INBIA, 2017).

A Associação Nacional de Entidades Promotoras de Empreendimentos Inovadores (ANPROTEC, 2019) considera quatro tipos de incubadoras: as incubadoras de empresas de base tecnológica, de setores tradicionais, mistas e sociais. As incubadoras de empresas de base tecnológica são destinadas a empresas que geram seus produtos e serviços por meio de pesquisa aplicada; as de setores tradicionais abrigam empresas que desejam agregar valor em seus produtos e serviços; as mistas congregam empreendimentos de base tecnológica e setores tradicionais; e as sociais abrigam cooperativas e associações populares.

Assim, com o principal objetivo de apoiar a inovação, as incubadoras de empresas de base tecnológica se constituem em mecanismos essenciais para 
gerar ambientes favoráveis a ideias inovadoras (BINSAWAD; SOHAIB; HAWRYSZKIEWYCZ, 2019; MAS-VERDÚ; RIBEIRO-SORIANO; ROIGTIERNO, 2015).

\section{METODOLOGIA}

Esta pesquisa é um estudo bibliográfico, de caráter exploratório e com abordagem quantitativa, elaborada a partir de uma análise bibliométrica sobre compartilhamento do conhecimento e incubadoras de empresas de base tecnológica. O método utilizado foi o Knowledge Development ProcessConstructivist (Proknow-C), desenvolvido por Ensslin e Ensslin (2007) e Ensslin et al. (2010) por meio de estudos no Laboratório de Metodologias Multicritério em Apoio à Decisão do Departamento de Engenharia de Produção e Sistemas da Universidade Federal de Santa Catarina (ENSSLIN; ENSSLIN; PINTO, 2013).

O Proknow-C consiste em um processo estruturado para análises de literatura, que possibilita a construção de um conhecimento para investigar um determinado tema (ENSSLIN; ENSSLIN; PINTO, 2012). A escolha do ProknowC se deu pela confiabilidade do método, uma vez que, em pesquisa inicial efetuada no Google Scholar utilizando o termo Proknow-C, observou-se uma quantidade representativa de trabalhos publicados que o utilizam. Além disso, o método possibilita a repetibilidade, o que garante credibilidade à pesquisa.

O Proknow-C é dividido em quatro etapas principais: (a) seleção do portfólio bibliográfico, (b) análise bibliométrica do portfólio, (c) análise sistêmica e (d) definição da pergunta de pesquisa e do objetivo de pesquisa. Dentre essas etapas, utilizou-se para este estudo apenas a primeira, pois vai ao encontro do objetivo desta pesquisa, que é evidenciar o estado da arte em publicações que relacionem o compartilhamento do conhecimento e incubadoras de empresas de base tecnológica. A seleção do portfólio bibliográfico é composta pelas fases de (a) seleção do banco de artigos bruto e (b) filtragem do banco de artigos bruto, que serão explicitadas a seguir. 


\subsection{Seleção do Banco de Artigos Bruto}

A fase de seleção do banco de artigos bruto engloba quatro processos: (a) definir palavras-chave, (b) definir bancos de dados, (c) buscar artigos nos bancos de dados com as palavras-chave; e (d) testar a aderência das palavraschave (ENSSLIN; ENSSLIN; PINTO, 2012). Esses processos estão representados na Figura 1 e são a seguir detalhados.

Figura 1 - Seleção do banco de artigos bruto

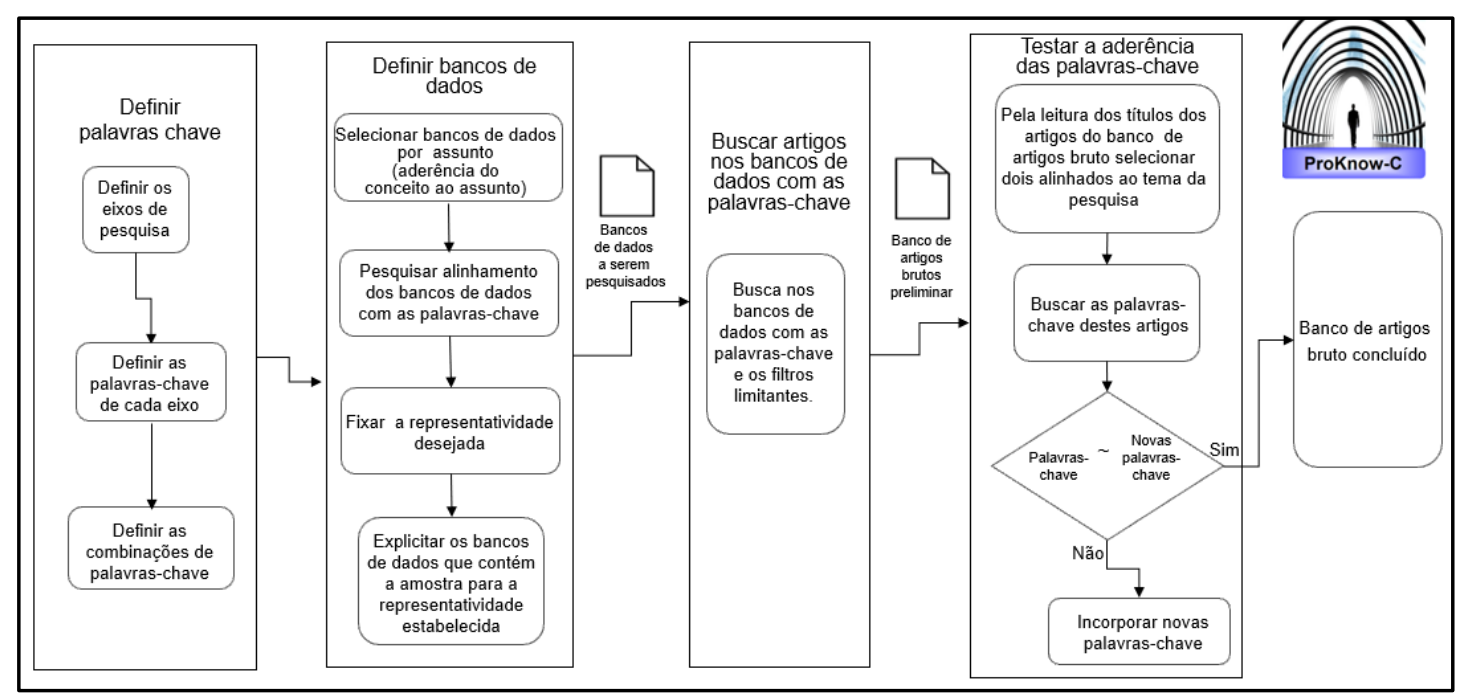

Fonte: Adaptado de Ensslin et al. (2010).

Para a definir as palavras-chave, inicialmente efetuou-se uma pesquisa no banco de dados ScienceDirect, selecionando e realizando a leitura de dois artigos relacionados ao tema compartilhamento do conhecimento e incubadoras de empresas, o que possibilitou identificar as palavras-chave e os eixos utilizados na pesquisa: eixo I, knowledge transfer e knowledge sharing, e eixo II, incubator, business incubator, technological business incubators, technological incubators, startups, entrepreneurial ecosystem e innovation ecosystem. As palavras-chave do eixo I foram individualmente combinadas com as palavraschave do eixo II, utilizando o operador $A N D$.

Para definir os bancos de dados, quatro são as atividades necessárias: selecionar os bancos de dados por assunto, pesquisar o alinhamento dos bancos de dados com as palavras-chave, fixar uma representatividade desejada e explicitar os bancos de dados que contém a amostra para a representatividade 
estabelecida. $O$ processo de definição dos bancos de dados e respectivas atividades são demonstrados na Figura 2.

Figura 2 - Definição dos bancos de dados

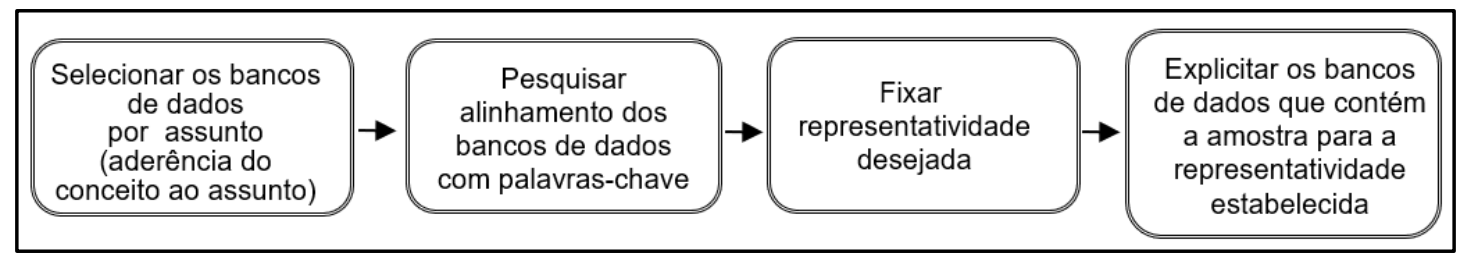

Fonte: Adaptado de Ensslin et al. (2010).

Para selecionar os bancos de dados por assunto foram realizadas buscas no Portal de Periódicos da Coordenação de Aperfeiçoamento de Pessoal de Nível Superior (Capes), filtrando por áreas do conhecimento. Desse modo, foram identificados 141 bancos de dados que abrangem a área de Ciências Sociais Aplicadas. Por meio da leitura do tipo de cada banco de dados e do conteúdo destes, selecionaram-se para a pesquisa os seguintes: Catálogo de Teses e Dissertações da Capes, Emerald, Scielo, Scopus, ScienceDirect e Web of Science. Para a segunda atividade, pesquisar alinhamento dos bancos de dados com as palavras-chave, foram efetuadas 14 pesquisas em cada banco de dados, utilizando as palavras-chave definidas no primeiro processo de seleção do banco de artigos bruto. Os dados foram agrupados, como demonstrado na Tabela 1.

Tabela 1 - Resultados das buscas nos bancos de dados

\begin{tabular}{l|c|c}
\hline \multicolumn{1}{c|}{ Bancos de dados } & $\begin{array}{c}\text { Resultado total das } \\
\text { buscas }\end{array}$ & $\begin{array}{c}\% \text { de } \\
\text { representação }\end{array}$ \\
\hline Scielo & 3 & 0,03 \\
\hline Catálogo de Teses e Dissertações da Capes & 9 & 0,09 \\
\hline Web of Science & 100 & 1,03 \\
\hline ScienceDirect & 1922 & 19,85 \\
\hline Emerald & 2174 & 22,45 \\
\hline Scopus & 5477 & 56,55 \\
\hline Total & 9.685 & 100 \\
\hline
\end{tabular}

Fonte: Elaborado pelos autores.

Em seguida, dado que o método Proknow-C atribui aos pesquisadores a definição de uma representatividade desejada (ENSSLIN et al., 2013), foi estabelecido que os bancos de dados que apresentassem percentual de 
representação inferior a $2 \%$ seriam excluídos. Diante disso, optou-se por desconsiderar os bancos de dados Scielo, Catálogo de Teses e Dissertações da Capes e Web of Science, uma vez que o percentual de representação dessas bases é de 0,03, 0,09 e 1,03, respectivamente. Assim, os bancos de dados que contém a amostra para a representatividade estabelecida são ScienceDirect, Emerald e Scopus.

Em direção à busca de artigos nos bancos de dados selecionados com as palavras-chave definidas, novas pesquisas de artigos foram efetuadas, utilizando-se as estratégias relacionadas no Quadro 1. As buscas foram realizadas em setembro de 2019.

Quadro 1 - Estratégia de busca por banco de dados

\begin{tabular}{|c|l|}
\hline $\begin{array}{c}\text { Bancos de } \\
\text { dados }\end{array}$ & \multicolumn{1}{|c|}{ Estratégias de busca } \\
\hline Scopus & $\begin{array}{l}\text { Busca por artigos, de acesso livre, com palavras-chave, em qualquer local } \\
\text { do artigo. }\end{array}$ \\
\hline Emerald & $\begin{array}{l}\text { Busca por artigos, de acesso livre, com palavras-chave, em qualquer local } \\
\text { do artigo. }\end{array}$ \\
\hline ScienceDirect & Busca no título, resumo ou palavras-chave especificadas por autor. \\
\hline
\end{tabular}

Fonte: Elaborado pelos autores.

Posterior a realização das buscas, os resultados foram sistematizados, como pode ser observado na Tabela 2.

Tabela 2 - Resultados das buscas por banco de dados

\begin{tabular}{|c|c|c|c|c|c|c|}
\hline Eixo I & Operador & Eixo II & $\begin{array}{l}\frac{D}{\pi} \\
\text { ฮั }\end{array}$ & 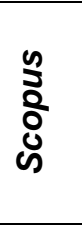 & 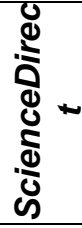 & $\begin{array}{l}\bar{\square} \\
\text { 음 }\end{array}$ \\
\hline \multirow{7}{*}{$\begin{array}{l}\text { "Knowledge } \\
\text { transfer" }\end{array}$} & $A N D$ & "incubator" & 10 & 62 & 6 & 78 \\
\hline & $A N D$ & "business incubator" & 4 & 29 & 4 & 36 \\
\hline & $A N D$ & "technological business incubators" & 0 & 3 & 1 & 3 \\
\hline & $A N D$ & "technological incubators" & 0 & 4 & 0 & 4 \\
\hline & $A N D$ & "startups" & 8 & 101 & 1 & 113 \\
\hline & $A N D$ & "entrepreneurial ecosystem" & 6 & 28 & 1 & 34 \\
\hline & $A N D$ & "innovation ecosystem" & 6 & 60 & 3 & 69 \\
\hline \multirow{7}{*}{$\begin{array}{l}\text { "Knowledge } \\
\text { sharing" }\end{array}$} & $A N D$ & "incubator" & 7 & 50 & 2 & 59 \\
\hline & $A N D$ & "business incubator" & 3 & 16 & 0 & 19 \\
\hline & $A N D$ & "technological business incubators" & 0 & 1 & 0 & 1 \\
\hline & $A N D$ & "technological incubators" & 0 & 1 & 0 & 1 \\
\hline & $A N D$ & "startups" & 11 & 92 & 1 & 104 \\
\hline & $A N D$ & "entrepreneurial ecosystem" & 2 & 11 & 0 & 14 \\
\hline & $A N D$ & "innovation ecosystem" & 3 & 30 & 1 & 35 \\
\hline \multicolumn{3}{|l|}{ Total } & 60 & 488 & 20 & 568 \\
\hline
\end{tabular}


Fonte: Elaborado pelos autores.

Os títulos de todos os artigos encontrados nos três bancos de dados foram exportados para uma planilha do Microsoft Excel, formando assim um banco de artigos preliminar.

Para testar a aderência das palavras-chave, o método sugere que, por meio da leitura dos títulos do banco de artigos preliminar, sejam identificados dois artigos alinhados com o tema e com as palavras-chave utilizadas, comparadas essas palavras-chave com aquelas utilizadas no início da pesquisa, e se constatadas novas palavras-chave, estas devem ser incorporadas e empregadas em uma nova busca. Se nessa etapa não houver novas palavraschave, deve-se prosseguir para a etapa seguinte.

Assim, efetuados os passos do teste de aderência acima relatados, incluiu-se a palavra-chave knowledge exchange no eixo I e, posteriormente, foram realizadas novas buscas nos três bancos de dados já definidos, cujos resultados são apresentados na Tabela 3.

Tabela 3 - Resultados da busca

\begin{tabular}{|c|c|c|c|c|c|c|}
\hline Eixo I & Operador & Eixo II & 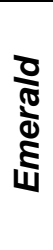 & 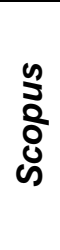 & 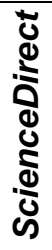 & $\begin{array}{l}\bar{\pi} \\
\text { 음 }\end{array}$ \\
\hline \multirow{7}{*}{$\begin{array}{l}\text { "Knowledge } \\
\text { exchange" }\end{array}$} & $A N D$ & "incubator" & 3 & 20 & 1 & 24 \\
\hline & $A N D$ & "business incubator" & 1 & 5 & 0 & 6 \\
\hline & $A N D$ & "technological business incubators" & 0 & 0 & 0 & 0 \\
\hline & $A N D$ & "technological incubators" & 0 & 0 & 0 & 0 \\
\hline & $A N D$ & "startups" & 6 & 23 & 0 & 29 \\
\hline & $A N D$ & "entrepreneurial ecosystem" & 0 & 5 & 0 & 5 \\
\hline & $A N D$ & "innovation ecosystem" & 0 & 10 & 1 & 11 \\
\hline \multicolumn{3}{|l|}{ Total } & 10 & 63 & 2 & 75 \\
\hline
\end{tabular}

Fonte: Elaborado pelos autores.

Com a realização dessas novas buscas, os resultados foram somados àqueles das buscas anteriores, criando, assim, um repositório com 643 artigos, denominado então de banco de artigos bruto. 


\subsection{Filtragem do Banco de Artigos Bruto}

A fase de filtragem do banco de artigos bruto é composta por quatro processos: (a) filtragem do banco de artigos bruto quanto à redundância, (b) filtragem do banco de artigos bruto não repetidos quanto ao alinhamento do título, (c) filtragem do banco de artigos bruto não repetidos e com título alinhado quanto ao reconhecimento científico e (d) filtragem quanto ao alinhamento do artigo integral.

A filtragem do banco de artigos bruto quanto à redundância é realizada por meio de duas atividades: importação dos artigos para um gerenciador bibliográfico e exclusão dos artigos repetidos. A filtragem quanto ao alinhamento do título compreende a leitura do título dos artigos com vistas a identificar a conformidade destes com os temas da pesquisa. Esses dois processos são representados na Figura 3.

\section{Figura 3 - Filtragens do banco de artigos bruto quanto à redundância e ao} alinhamento do título

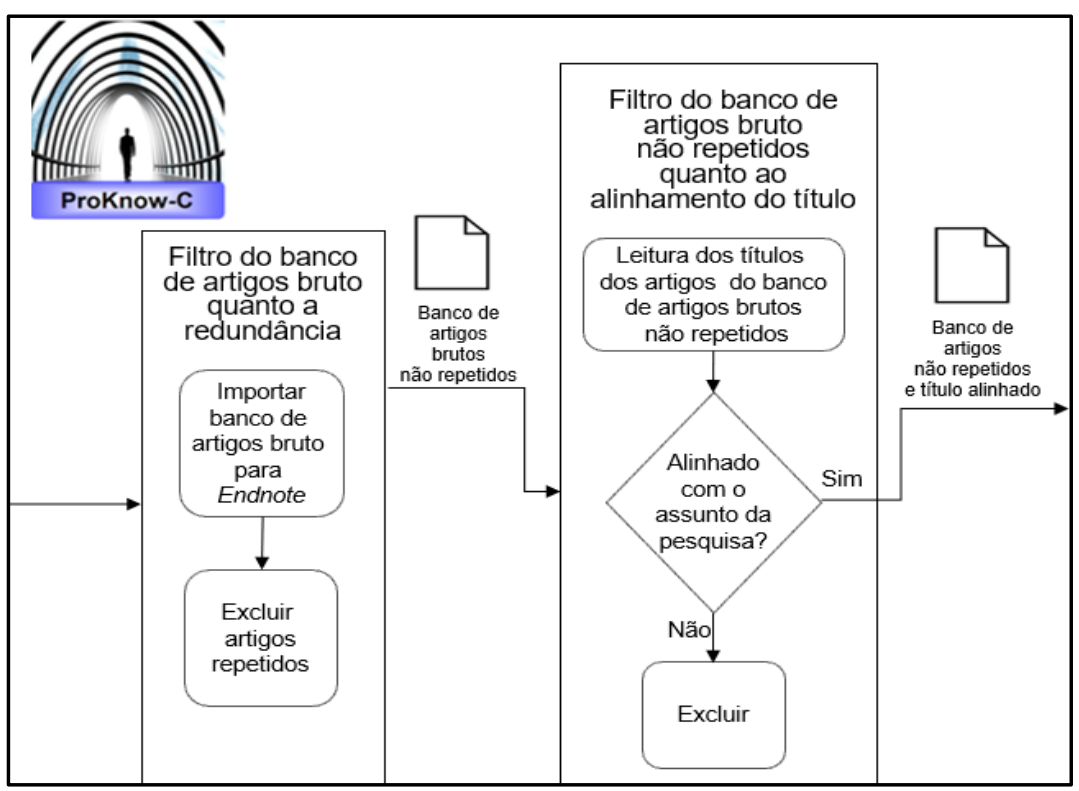

Fonte: Ensslin et al. (2010).

A filtragem do banco de artigos bruto não repetidos e com título alinhado quanto ao reconhecimento científico é realizada a partir da determinação do número de citações de cada artigo. Para tanto, cria-se uma planilha contendo os títulos dos artigos e respectivos número de citações e percentual de participação. 
Na sequência, é estabelecido um valor de representatividade das publicações, a partir do número de citações, que é utilizado como ponto de corte para distinguir os artigos com e sem reconhecimento científico confirmado. Aqueles que têm reconhecimento científico confirmado são submetidos à leitura do resumo e se alinhados ao tema da pesquisa, compõem o repositório $A$. Em seguida, são identificados os autores de cada um dos artigos desse repositório, formando assim um banco de autores.

Os artigos com reconhecimento científico ainda não confirmado são avaliados quanto ao ano de publicação. Para tanto, são separados em dois grupos: publicados com menos ou com mais de dois anos. Aqueles publicados há menos de dois anos são submetidos à leitura do resumo e se alinhados ao tema da pesquisa, compõem o repositório B. Os artigos publicados a mais de dois anos têm seus autores comparados com os autores do repositório $A$. Caso haja semelhança, efetua-se a leitura do resumo e se alinhados ao tema da pesquisa, são incorporados ao repositório B. A fusão dos repositórios $A$ e $B$ formam o repositório $C$, que é a atividade final da filtragem do banco de artigos bruto não repetidos e com título alinhado quanto ao reconhecimento científico. Esse processo é demonstrado na Figura 4.

Figura 4 - Filtragem do banco de artigos bruto quanto ao reconhecimento científico

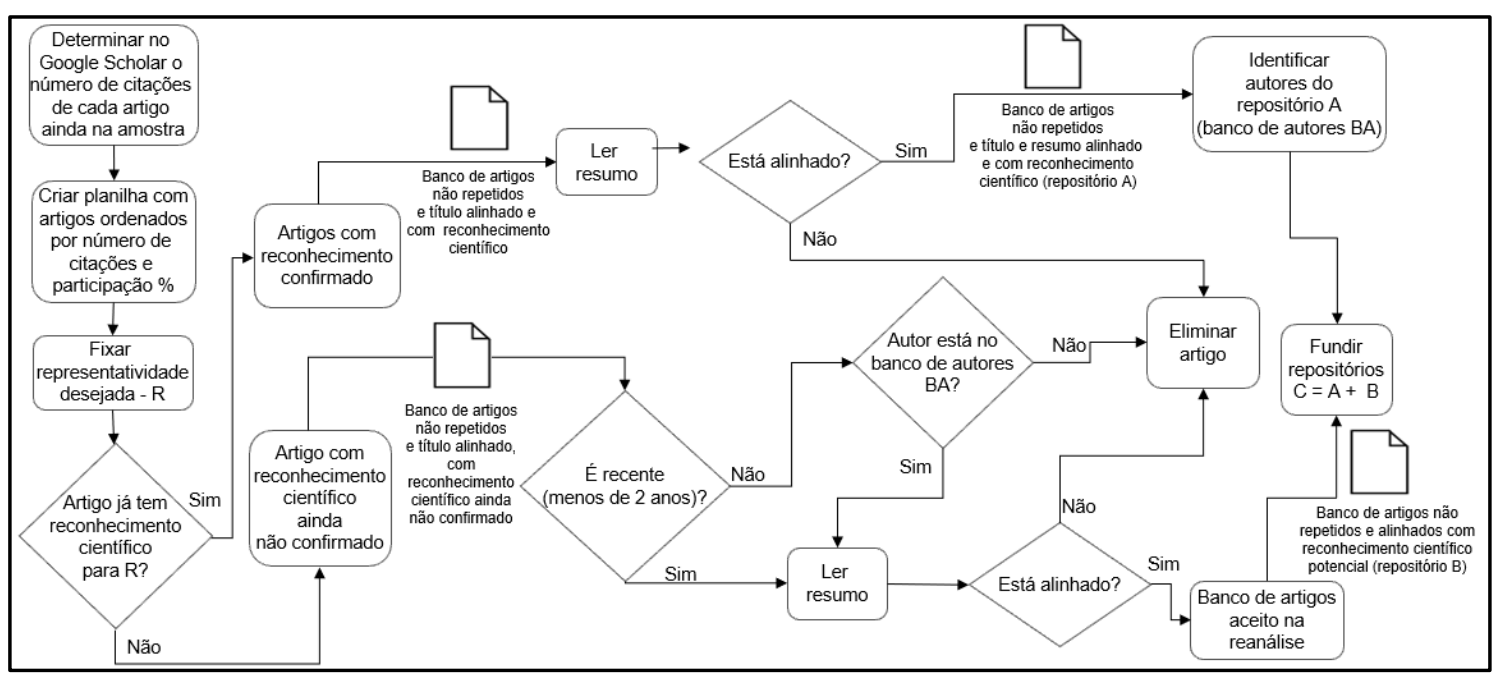

Fonte: Adaptado de Ensslin et al. (2010). 
Por fim, a filtragem quanto ao alinhamento do artigo integral é realizada mediante a verificação de disponibilidade para leitura na íntegra. Os artigos disponíveis são submetidos à leitura no intuito de identificar o alinhamento com os temas da pesquisa.

O processo de filtragem do banco de artigos bruto referente à redundância foi executado a partir da exportação dos títulos das 643 publicações, resultantes da busca nas bases de dados selecionadas, para uma planilha do Microsoft Excel, os quais foram ordenados alfabeticamente para melhor visualizar os artigos duplicados, e da exclusão daqueles que se repetiam. Desse modo, chegou-se a um número de 378 publicações para compor o banco de artigos bruto não repetidos.

A filtragem quanto ao alinhamento do título foi efetuada a partir da leitura dos títulos de todos os trabalhos do banco de artigos bruto não repetidos (378). Considerou-se como alinhados ao título aqueles que contém os termos troca, compartilhamento e transferência de conhecimento e/ou ambientes de inovação, como incubadoras, incubadoras de empresas, startups e ecossistemas de inovação. Assim, foram selecionados 37 trabalhos para compor o banco de artigos não repetidos e com títulos alinhados ao tema da pesquisa.

Para a filtragem relacionada ao reconhecimento científico, verificouse no Google Scholar o número de citações desses 37 trabalhos selecionados. Os resultados foram contabilizados em uma planilha, em ordem crescente, totalizando 715 citações. Em seguida, foi estabelecido um valor de representatividade das publicações, a partir do número de citações. Não existe um parâmetro para determinar essa representatividade, apenas uma recomendação de que compreenda, ao menos, $85 \%$ do total das citações (AFONSO et al., 2011). Nesse sentido, foi estabelecido como ponto de corte os artigos que possuem 10 ou mais citações, totalizando 17 artigos. Estes 17 artigos somam 657 citações, o que representa $91,89 \%$ das 715 citações, cumprindo, desse modo, com a recomendação do método utilizado. 


\section{Gráfico 1 - Quantidade de citações e ponto de corte para a representatividade desejada das publicações}

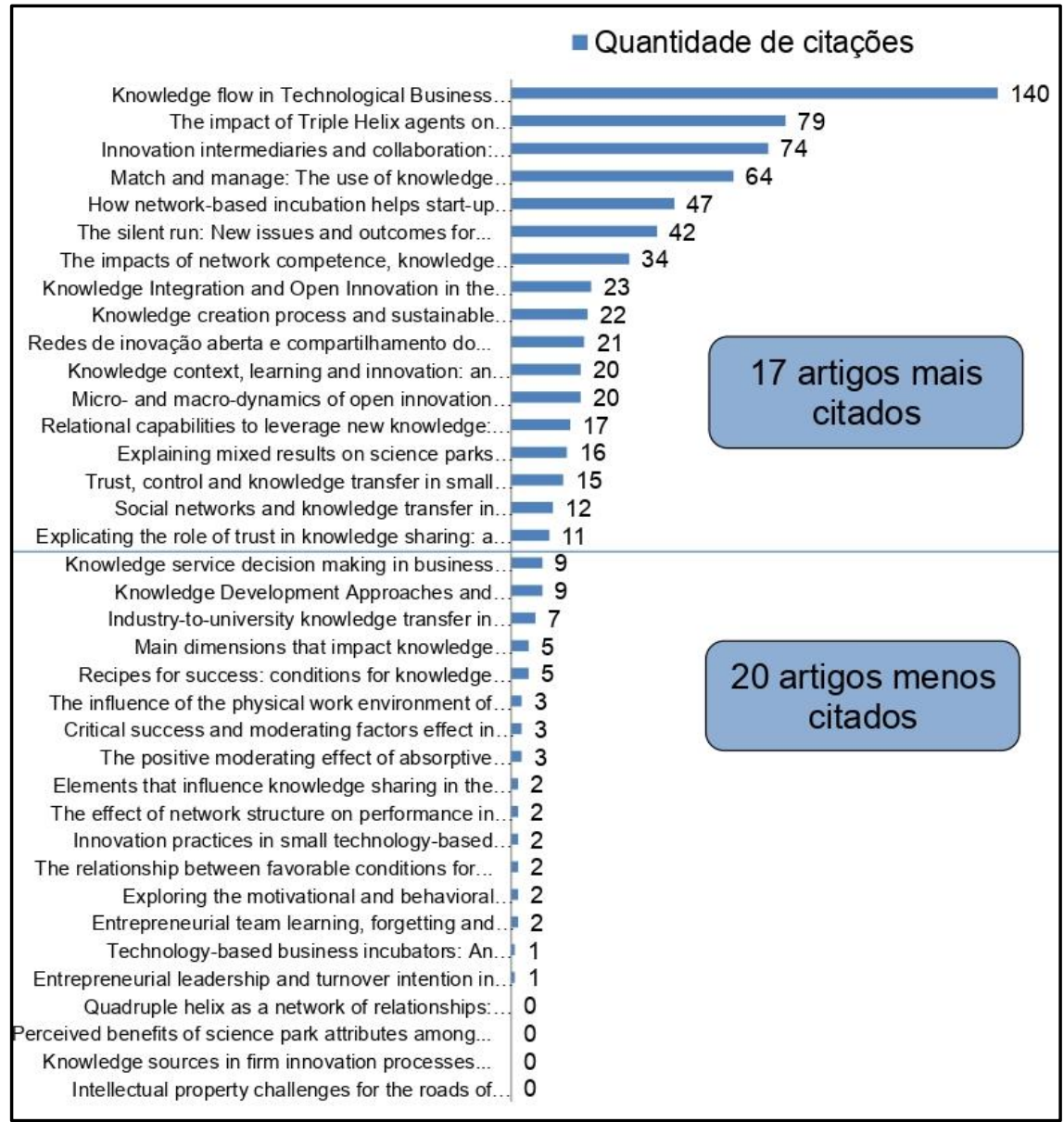

Fonte: Elaborado pelos autores.

Posteriormente, efetuou-se a leitura do resumo desses 17 artigos com reconhecimento científico, sendo que oito foram considerados para compor o repositório $A$ em razão do alinhamento ao tema da pesquisa.

Os 20 artigos com reconhecimento científico não confirmado foram analisados quanto ao ano de publicação. Assim, verificou-se que um artigo foi publicado no ano de 2012 e 19 a partir de 2017. Como sugere o método, foi efetuada a leitura do resumo desses 19 artigos, sendo que 15 foram considerados alinhados ao tema da pesquisa e, portanto, com reconhecimento científico em potencial, compondo assim o repositório B. Em relação ao trabalho publicado no ano de 2012, seus autores foram comparados aos autores dos artigos do repositório $A$, e como não houve correspondência entre eles, o artigo 
foi eliminado. A fusão dos repositórios $A$ e $B$ deu origem ao repositório $C$, composto por 23 artigos.

Por fim, a filtragem do banco de artigos bruto quanto ao alinhamento do artigo integral foi efetuada a partir da verificação da disponibilidade da leitura completa dos artigos do repositório $\mathrm{C}$. Desse modo, após a leitura integral foram selecionados nove artigos que, na percepção dos autores, estão alinhados ao tema deste estudo.

Posteriormente, efetuou-se a leitura do resumo desses 17 artigos com reconhecimento científico, sendo que oito foram considerados para compor 0 repositório $A$ em razão do alinhamento ao tema da pesquisa.

Os 20 artigos com reconhecimento científico não confirmado foram analisados quanto ao ano de publicação. Assim, verificou-se que um artigo foi publicado no ano de 2012 e 19 a partir de 2017. Como sugere o método, foi efetuada a leitura do resumo desses 19 artigos, sendo que 15 foram considerados alinhados ao tema da pesquisa e, portanto, com reconhecimento científico em potencial, compondo assim o repositório B. Em relação ao trabalho publicado no ano de 2012, seus autores foram comparados aos autores dos artigos do repositório $A$, e como não houve correspondência entre eles, o artigo foi eliminado. A fusão dos repositórios $\mathrm{A}$ e $\mathrm{B}$ deu origem ao repositório $\mathrm{C}$, composto por 23 artigos.

Por fim, a filtragem do banco de artigos bruto quanto ao alinhamento do artigo integral foi efetuada a partir da verificação da disponibilidade da leitura completa dos artigos do repositório $\mathrm{C}$. Desse modo, após a leitura integral foram selecionados nove artigos que, na percepção dos autores, estão alinhados ao tema deste estudo.

\section{ANÁLISE DOS DADOS}

A partir da seleção do portfólio bibliográfico, iniciou-se o processo de análise dos dados, levando em consideração quatro critérios: ano de publicação, número de citações, periódico e palavras-chaves.

Quanto ao ano de publicação, os estudos selecionados compreendem o 
período de 2009 a 2019. Nesse intervalo de tempo, destacam-se os anos de 2019 com três estudos e 2017 com dois. As publicações apresentam uma tímida tendência de crescimento, o que sugere um interesse recente pelas temáticas pesquisadas, conforme mostrado no Gráfico 2.

\section{Gráfico 2 - Quantidade de publicações por ano}

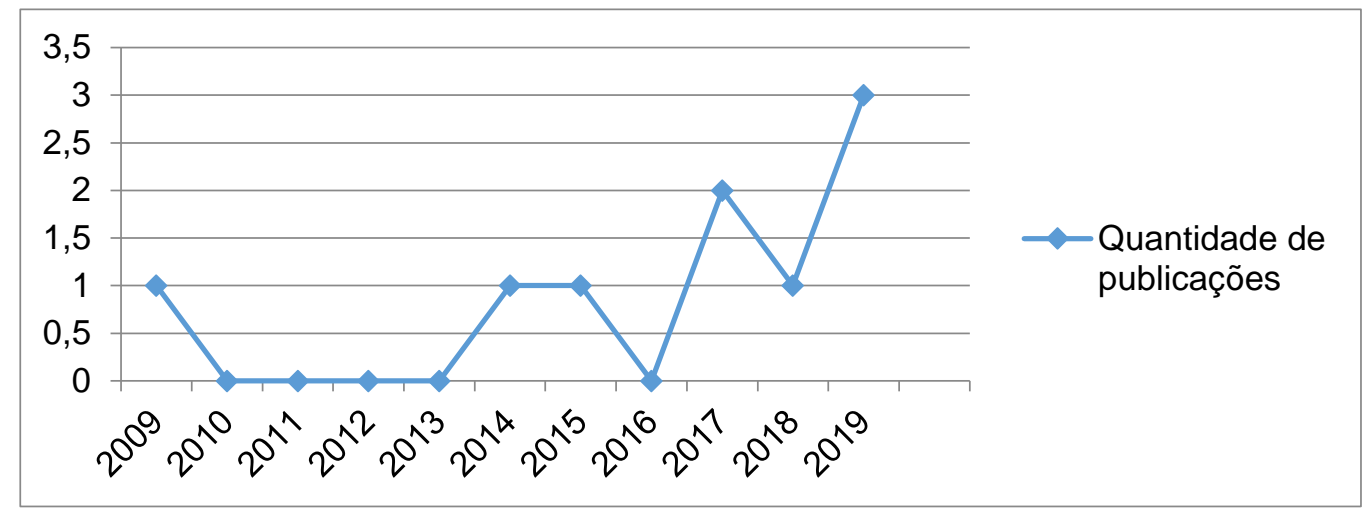

Fonte: Elaborado pelos autores.

A análise quanto ao número de citações avalia o reconhecimento científico do portfólio. Nesse sentido, na Tabela 4 relacionam-se os artigos selecionados e respectivos ano de publicação, número de citações e percentual de representação. É possível observar que, com exceção dos dois artigos com maior número de citações, a relação entre o número de citações e o ano de publicação é inversamente proporcional, ou seja, quanto mais recente a publicação menor o número de citações.

Tabela 4 - Artigos selecionados e o número de citações

\begin{tabular}{l|c|c|c}
\hline \multicolumn{1}{c|}{ Tótulo } & $\begin{array}{c}\text { Ano de } \\
\text { publicação }\end{array}$ & $\begin{array}{c}\text { Quantidade } \\
\text { de citações }\end{array}$ & $\begin{array}{c}100 \\
\% \text { de } \\
\text { representação }\end{array}$ \\
\hline $\begin{array}{l}\text { Perceived benefits of science park } \\
\text { attributes among park tenants in the } \\
\text { Netherlands }\end{array}$ & 2019 & 0 & 0 \\
\hline $\begin{array}{l}\text { Technology-based business incubators: } \\
\text { exploratory analysis of intra- } \\
\text { organizational social networks }\end{array}$ & 2019 & 1 & 0,47 \\
\hline $\begin{array}{l}\text { Recipes for success: conditions for } \\
\text { knowledge transfer across open innovation } \\
\text { ecosystems }\end{array}$ & 2019 & 5 & 2,34 \\
\hline $\begin{array}{l}\text { Knowledge service decision making in } \\
\text { business incubators based on the } \\
\text { supernetwork model }\end{array}$ & 2017 & 9 & 4,20 \\
\hline $\begin{array}{l}\text { Explicating the role of trust in knowledge } \\
\text { sharing: a structural equation model test }\end{array}$ & 2017 & 11 & 5,14 \\
\hline
\end{tabular}




\begin{tabular}{l|c|c|c}
\hline $\begin{array}{l}\text { Social networks and knowledge transfer in } \\
\text { technological park companies in Brazil. }\end{array}$ & 2014 & 12 & 5,61 \\
\hline $\begin{array}{l}\text { Explaining mixed results on science parks } \\
\text { performance: Bright and dark sides of the } \\
\text { effects of inter-organisational knowledge } \\
\text { transfer relationships }\end{array}$ & 2009 & 16 & 7,48 \\
\hline $\begin{array}{l}\text { Knowledge context, learning and } \\
\text { innovation: an integrating framework }\end{array}$ & 2018 & 20 & 9,34 \\
\hline $\begin{array}{l}\text { Knowledge flow in Technological Business } \\
\text { Incubators: Evidence from Australia and } \\
\text { Israel }\end{array}$ & 2015 & 140 & 65,42 \\
\hline
\end{tabular}

Fonte: Elaborado pelos autores.

Dentre os artigos com maior percentual de citações $(82,84 \%)$ destacamse: "Knowledge flow in Technological Business Incubators: Evidence from Australia and Israel", de Rubin, Aas e Stead (2015); "Knowledge context, learning and innovation: an integrating framework", de Roper e Love (2018); e "Explaining mixed results on science parks performance: Bright and dark sides of the effects of inter-organisational knowledge transfer relationships", de Chan, Oerlemans e Pretorius (2009).

Em relação aos periódicos, observa-se que não há incidência de publicações no mesmo meio de divulgação. Nesse sentido, não foi possível evidenciar os periódicos com maior número de publicações no tema em questão, como demonstrado no Quadro 2.

\section{Quadro 2 - Periódicos e artigos do portfólio}

\begin{tabular}{|c|c|}
\hline Periódico & Título \\
\hline $\begin{array}{l}\text { The Journal of Technology } \\
\text { Transfer }\end{array}$ & $\begin{array}{l}\text { Perceived benefits of science park attributes among park } \\
\text { tenants in the Netherlands }\end{array}$ \\
\hline $\begin{array}{l}\text { Innovation \& Management } \\
\text { Review }\end{array}$ & $\begin{array}{l}\text { Technology-based business incubators: An exploratory } \\
\text { analysis of intra-organizational social networks }\end{array}$ \\
\hline $\begin{array}{l}\text { International Journal of } \\
\text { Information Management }\end{array}$ & $\begin{array}{l}\text { Recipes for success: conditions for knowledge transfer } \\
\text { across open innovation ecosystems }\end{array}$ \\
\hline $\begin{array}{l}\text { Physica A: Statistical } \\
\text { Mechanics and its Applications }\end{array}$ & $\begin{array}{l}\text { Knowledge service decision making in business incubators } \\
\text { based on the supernetwork model }\end{array}$ \\
\hline $\begin{array}{l}\text { Journal of Business } \\
\text { Economics and Management }\end{array}$ & $\begin{array}{l}\text { Explicating the role of trust in knowledge sharing: a } \\
\text { structural equation model test }\end{array}$ \\
\hline $\begin{array}{l}\text { Journal of Technology } \\
\text { Management \& Innovation }\end{array}$ & $\begin{array}{l}\text { Social networks and knowledge transfer in technological } \\
\text { park companies in Brazil. }\end{array}$ \\
\hline $\begin{array}{l}\text { South African Journal of } \\
\text { Industrial Engineering }\end{array}$ & $\begin{array}{l}\text { Explaining mixed results on science parks performance: } \\
\text { Bright and dark sides of the effects of inter-organisational } \\
\text { knowledge transfer relationships }\end{array}$ \\
\hline $\begin{array}{l}\text { Journal } \\
\text { Industry and Innovat }\end{array}$ & $\begin{array}{l}\text { Knowledge context, learning and innovation: an integrating } \\
\text { framework }\end{array}$ \\
\hline
\end{tabular}

Inf. Inf., Londrina, v. 26, n. 1, p. 264 - 288, jan./mar. 2021. 


\begin{tabular}{|l|l|}
\hline Technovation & $\begin{array}{l}\text { Knowledge flow in Technological Business Incubators: } \\
\text { Evidence from Australia and Israel }\end{array}$ \\
\hline
\end{tabular}

Fonte: Elaborado pelos autores

A análise das palavras-chave do portfólio bibliográfico indica a ocorrência de 29 termos distintos: enabling technology; facilities and services; knowledge transfer; learning; sector; technology park; ambition; business incubation; cocreation; culture of trust; digital social networks; ecosystem; fuzzy-set qualitative comparative analysis; innovation/innovation networks; knowledge networking service; knowledge sharing; knowledge/knowledge management; open innovation; optimal decision; organizational behaviour; perceived benefts; real estate; science parks; social identity theory; social network; structural equation model test; supernetwork; technological business incubators e technology transfer. Dentre estes termos, alguns aparecem em diferentes artigos. No Gráfico 3 destacam-se as palavras-chave utilizadas por pelo menos dois artigos distintos.

\section{Gráfico 3 - Quantidade de palavras-chave que se repetem.}

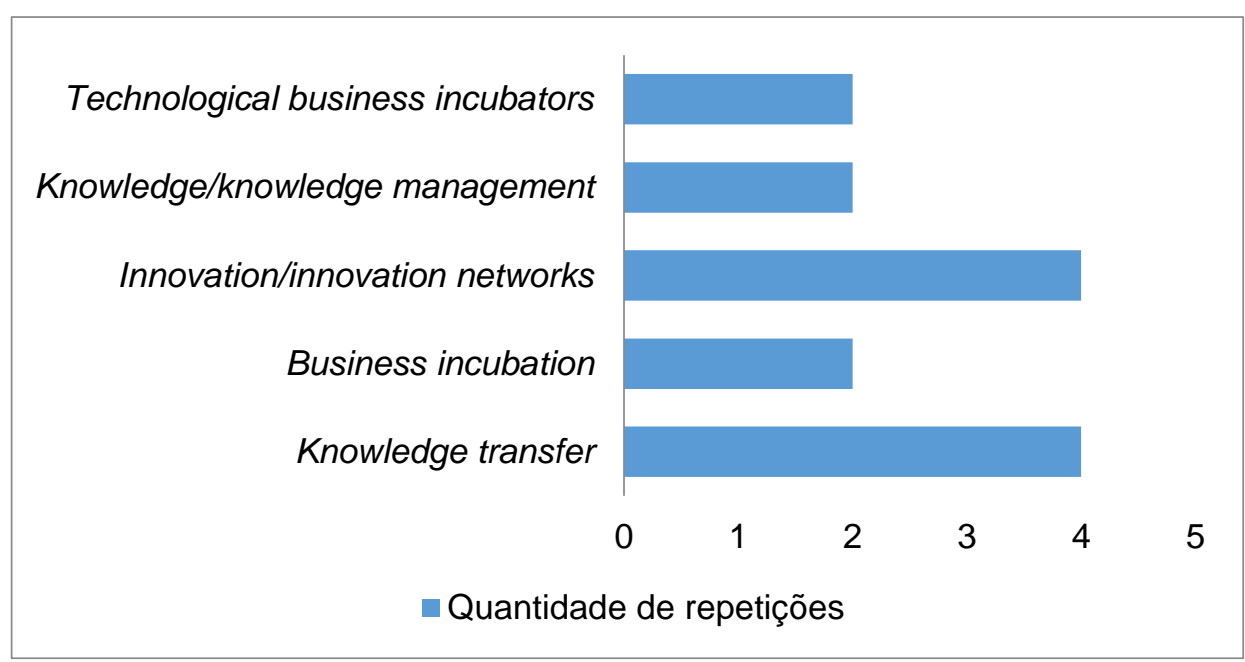

Fonte: Elaborado pelos autores.

Assim, como pode ser verificado no Gráfico 3, as palavras-chave que aparecem com maior frequência nos artigos são technological business incubators, knowledge/knowledge management, innovation/innovation networks, business incubation e knowledge transfer. Todas estão relacionadas aos eixos utilizados na pesquisa, corroborando a aderência dessas palavras na busca em 
relação ao tema da pesquisa.

\section{CONSIDERAÇÕES FINAIS}

Diante da importância de desenvolver estudos que relacionem os temas compartilhamento do conhecimento e ambientes de inovação, principalmente incubadoras de empresas, este trabalho teve por objetivo evidenciar o estado da arte em publicações que relacionem o compartilhamento do conhecimento e incubadoras de empresas de base tecnológica.

Para tanto, foram realizadas análises em relação ao ano de publicação, número de citações, periódico e palavras-chave. Em relação ao ano de publicação, apesar de não haver recorte temporal nas buscas, os estudos encontrados foram publicados no período de 2009 a 2019. Apesar do reduzido número do banco de artigos, foi possível observar uma pequena tendência de crescimento das publicações nos temas pesquisados.

A análise das citações permitiu identificar o reconhecimento científico dos estudos selecionados. $\mathrm{O}$ artigo intitulado "Knowledge flow in Technological Business Incubators: Evidence from Australia and Israel" foi o mais relevante, com 140 citações. Também foi possível observar que quanto mais recente a publicação menor o número de citações.

Em relação aos periódicos, não houve incidência de publicações no mesmo meio de divulgação. E quanto às palavras-chave mais utilizadas, os destaques foram para: technological business incubators, knowledge/knowledge management, innovation/innovation networks, business incubation e knowledge transfer, o que demonstra a aderência desses termos ao tema da pesquisa.

Cabe ressaltar que, partindo do objetivo deste estudo, não se pretende buscar a construção de um referencial teórico. Desse modo, como sugestão de estudos futuros, recomenda-se a análise do conteúdo deste portfólio encontrado.

\section{REFERÊNCIAS}

AFONSO, Michele HF et al. Como construir conhecimento sobre o tema de pesquisa? Aplicação do processo Proknow-C na busca de literatura sobre 
avaliação do desenvolvimento sustentável. Revista de Gestão Social e Ambiental, v. 5, n. 2, p. 47-62, 2011.

ALCARÁ, Adriana Rosecler et al. Fatores que influenciam o compartilhamento da informação e do conhecimento. Perspectivas em ciência da informação, v.14, n.1, p.170-191, 2009. Disponível em:

http://www.scielo.br/scielo.php?pid=S141399362009000100012\&script=sci_abs tract\&tlng=pt . Acesso em: 12 dez. 2019.

ANTUNES, Luiz Guilherme Rodrigues et al. Modelo de Negócio de Incubadoras de Empresas: Revisão de Escopo. Revista de Administração, Sociedade e Inovação, v. 5, n. 2, p. 144-161, 2019. Disponível em: http://www.rasi.vr.uff.br/index.php/rasi/article/view/282. Acesso em: 29 fev. 2020.

ASSOCIAÇÃO NACIONAL DE ENTIDADES PROMOTORAS DE EMPREENDIMENTOS INOVADORES. Incubadora de empresas. Disponível em: http://www.anprotec.org.br/. Acesso em: 28 dez. 2019.

BINSAWAD, Muhammad; SOHAIB, Osama; HAWRYSZKIEWYCZ, Igor. Factors impacting technology business incubator performance. International Journal of Innovation Management, v. 23, n. 1, p. 1-30, 2019.

COMISSÃO EUROPEIA DE NORMALIZAÇÃO. European Guide to good Practice in Knowledge Management - Part 1: Knowledge Management Framework.[s.l: s.n.], 2004. Disponível em:

http://www.fraserhealth.ca/media/Euro GuidetogoodpracticeinKMPart1.pdf. Acesso em: 15 fev. 2020.

CYR, Sylvio; $\mathrm{CHOO}$, Chun Wei. The individual and social dynamics of knowledge sharing: an exploratory study. Journal of Documentation, v.66, n. 6, p.824-846, 2010.

DALKIR, Kimiz. Knowledge Management in Theory and Practice. Cambridge, MA: MIT Press, 2017.

DOROW, Patrícia Fernanda; CALLE, Guillermo Antonio Dávila; RADOS, Gregório Jean Varvakis. Ciclo de conhecimento como gerador de valor: Uma proposta integradora. Revista ESPACIOS, v.36, n.12, 2015. Disponível em: https://www.revistaespacios.com/a15v36n12/15361213.html. Acesso em: 12 jan. 2020.

ENSSLIN, Leonardo; ENSSLIN, Sandra Rolim; PINTO, Hugo de Moraes. Processo de investigação e Análise bibliométrica: Avaliação da Qualidade dos Serviços Bancários. Revista de Administração Contemporânea, v.17, n.3, p.325-349, 2013. Disponível em: http://www.scielo.br/scielo.php?pid=S141565552013000300005\&script=sci_abstract\&tlng=pt. Acesso em: 22 dez. 2019. 
ENSSLIN, Sandra Rolim et al. Evidenciação do estado da arte do tema avaliação do desempenho na regulação de serviços públicos segundo a percepção dos pesquisadores. Gestão Pública: Práticas e Desafios, v. 4, n. $1,2013$.

ENSSLIN, L. et al. ProKnow-C, knowledge development process constructivist. Processo técnico com patente de registro pendente junto ao INPI. 2010.

FAORO, Roberta Rodrigues; OLIVEIRA, Mírian. Compartilhamento do conhecimento intra-organizacional e interorganizacional: Empresas do setor de fruticultura. Perspectivas em Gestão \& Conhecimento, v. 4, n. 1, p. 98-118, 2014. Disponível em: https://dialnet.unirioja.es/servlet/revista?codigo $=16256$. Acesso em: 13 jan. 2020.

FAROOQ, Rayees. A conceptual model of knowledge sharing. International Journal of Innovation Science, v.11, n.1, p.139-160, 2018.

INTERNATIONAL BUSINESS INCUBATION ASSOCIATION. Operational Definitions: Entrepreneurship Centers (Incubators, Accelerators, Coworking Spaces and Other Entrepreneurial Support Organizations). 2017. Disponível em: https://inbia.org/. Acesso em: 20 dez. 2019.

JIAN, Zhaoquan; WANG, Chen. The impacts of network competence, knowledge sharing on service innovation performance: Moderating role of relationship quality. Journal of Industrial Engineering and Management, v.6, n.1, p.25-49, 2013. Disponível em: https://www.jiem.org/index.php/jiem/article/view/659/343. Acesso em: 17 dez. 2019.

KÜHL, Marcos Roberto; DA CUNHA, João Carlos. Obstáculos à implementação de inovações no Brasil: como diferentes empresas percebem sua importância. BBR-Brazilian Business Review, v. 10, n. 2, p. 1-25, 2013. Disponível em: https://www.redalyc.org/pdf/1230/123027923001.pdf. Acesso em: 19 dez. 2019.

LIAO, Shu-Hsien; FEI, Wu-Chen; CHEN, Chih-Chiang. Knowledge sharing, absorptive capacity, and innovation capability: an empirical study of Taiwan's knowledge-intensive industries. Journal of Information Science, v.33, n.3, p.340-359, 2007.

MACHADO, Hilka Pelizza Vier; SILVA, Giane Shirley da; BORTOLOZZI, Flavio. Conhecimento em empresas de pequena dimensão no setor de construção civil. Informação\&Informação, v. 23, n. 2, p. 493 - 519, 2018. Disponível em: http://www.uel.br/revistas/uel/index.php/informacao/article/view/29590/24214. Acesso em: 05 mai. 2020. 
MAS-VERDÚ, Francisco; RIBEIRO-SORIANO, Domingo; ROIG-TIERNO, Norat. Firm survival: The role of in-cubators and business characteristics. Journal of Business Research, v.68, n.4, p.793-796, 2015.

MIRANDA, Maria Gabriela; BORGES, Renata. Technology-based business Incubators: An exploratory analysis of intra-organizational social networks. Innovation\& Management Revie, v.16, n.1, p.36-54, 2019. Disponível em: https://www.emerald.com/insight/content/doi/10.1108/INMR-04-20180017/full/html. Acesso em: 12 dez. 2019.

NAIM, Mohammad Faraz; LENKLA, Usha. Knowledge sharing as an intervention for Gen Y employees' intention to stay. Industrial and Commercial Training, v.48, n.3, p.142-148, 2016.

NAVIMIPOUR, Nima Jafari; CHARBAND, Yeganeh. Knowledge sharing mechanisms and techniques in project teams: literature review, classification, and current trends.Computers in Human Behavior; v.62, p.730-742, 2016.

PICININ, Claudia Tania; KOVALESKI, João Luiz; RAIMUNDI, Claudiani Vieira. Gestão do Conhecimento e inovação: um enfoque logístico. Revista Eletrônica Fafit/Facic, v.1, n.1, 2010. Disponível em: http://www.fafit.com.br/revista/index.php/fafit/article/view/8. Acesso em: 15 dez. 2019.

PIETROVSKI, Eliane Fernandes et al. Habitats de inovação tecnológica. In: CONGRESSO DE PESQUISA E INOVAÇÃO DA REDE NORTE NORDESTE DE EDUCAÇÃO TECNOLÓGICA - CONNEPI. Maceió. Anais... Maceió: CONNEPI, 2010. Disponível em: http://connepi.ifal.edu.br/ocs/anais/. Acesso em: 28 dez. 2019.

RAUPP, Fabiano Maury; BEUREN, Ilse Maria. O suporte das incubadoras brasileiras para potencializar as características empreendedoras nas empresas incubadas. Revista de Administração, v.41, n.4, p.419-430, 2006. Disponível em: http://www.spell.org.br/documentos/ver/16958/o-suporte-das-incubadorasbrasileiras-para-potencializar-as-caracteristicas-empreendedoras-nasempresas-incubadas/i/pt-br/. Acesso em: 27 dez. 2019.

RIEGE, Andreas. Three-dozen knowledge-sharing barriers managers must consider. Journal of knowledge management, v.9, n.3, p.18-35, 2005. Disponível em: http://citeseerx.ist.psu.edu/viewdoc/download?doi=10.1.1.453.5258\&rep=rep1\&t ype=pdf. Acesso em 29 dez. 2019.

SCARABELLI, Bruna Hernandes; SARTORI, Rejane; MENEGASSI, Cláudia Herrero Martins. Práticas de Gestão do Conhecimento em pequenas e médias empresas. In:CONGRESSO INTERNACIONAL DE CONHECIMENTO E INOVAÇÃO-CIKI. [S.I.], v.1, n.1, novembro 2019. ISSN 2318-5376. Disponível em: http://proceeding.ciki.ufsc.br/index.php/ciki/article/view/674. Acesso em: 03 jan. 2020. 
SMALIUKIENE, Rasa, et al. Explicating the Role of Trust in Knowledge Sharing: A Structural Equation Model Test. Journal of Business Economics and Management, v.18, p.758-78, 2017.

STYHRE, Alexander et al. Heedful interrelating, knowledge sharing, and new drug development. Journal of Knowledge Management, v.12, n.3, p.127-140, 2008.

TONET, Helena Correa; PAZ, Maria das Graças Torres da. Um modelo para o compartilhamento de conhecimento no trabalho. Revista de Administração Contemporânea, v.10, n.2, p.75-94, 2006. Disponível em: http://www.scielo.br/scielo.php?pid=S141565552006000200005\&script=sci_arttext\&tlng=pt. Acesso em: 18 jan. 2020.

VELMURUGAN, Manivannan; KOGILAH, Narayanasamy; DEVINAGA, Rasiah. Knowledge sharing in virtual teams in malaysia: Its benefits and barriers.

Journal of Information \& Knowledge Management, v.9, n.02, p.145-159, 2010.

YANG, Jen-te. The impact of knowledge sharing on organizational learning and effectiveness. Journal of Knowledge Management, v.11 n.2, p.83-90, 2007.

YOUNG Ronald. Management Tools and Techniques Manual. Asian

Productivity OrganizationKnowledge - APO, 2020. Disponível em: www.apotokyo.org. Acesso em: 03 mar. 2020.

ZHAO, Liming; ZHANG, Haihong; WU, Wenqing. Knowledge service decision making in business incubators based on the supernetwork model, Physica A:

Statistical Mechanics and its Applications, v.479, p.249-264, 2017.

\title{
KNOWLEDGE SHARING IN BUSINESS INCUBATORS: THE STATE OF ART FROM A BIBLIOMETRIC ANALYSIS
}

\begin{abstract}
Introduction: Knowledge sharing is considered the most important knowledge management process, contributing to the development of competitive advantages. In business incubators it is no different, as incubated companies lack knowledge resources for their development, which are made possible through knowledge sharing. Objective: To highlight the state of the art in publications that relate knowledge sharing and incubators of technology-based companies. Methodology: Bibliometric analysis based on the Knowledge Development Process-Constructivist (Proknow-C) method, carried out in the Emerald, Scopus and ScienceDirect databases, with no time frame. Results: Articles relating to the themes of knowledge sharing and incubators of technology-based companies began to be published in 2009 , with a timid growth trend in the following years. In accordance with the finding that this is an area that is still incipient in terms of scientific publications, the articles found do not have a high number of citations. It was not possible to highlight the journals with the highest number of publications on the
\end{abstract}


researched theme. The keywords found show adherence with those used in database searches. Conclusions: Based on the general objective of this study, this article highlights the state of the art of related topics. Nine studies were selected to compose the bibliographic portfolio. The analysis of the content of the portfolio found is presented as a suggestion for a future study.

Descriptors: Knowledge management. Knowledge sharing. Bibiometric analysis.

\title{
COMPARTIR CONOCIMIENTOS EN INCUBADORAS DE NEGOCIOS: EL ESTADO DEL ARTE A PARTIR DE UN ANÁLISIS BIBLIOMÉTRICO
}

\begin{abstract}
RESUMEN
Introducción: El intercambio de conocimientos se considera el proceso de gestión del conocimiento más importante, ya que contribuye al desarrollo de ventajas competitivas. En las incubadoras de empresas no es diferente, ya que las empresas incubadas carecen de recursos de conocimiento para su desarrollo, que son posibles gracias al intercambio de conocimientos. Objetivo: Destacar el estado del arte en publicaciones que relacionan el intercambio de conocimiento e incubadoras de empresas de base tecnológica. Metodología: Análisis bibliométrico basado en el método Constructivista del Proceso de Desarrollo del Conocimiento (Proknow-C), realizado en las bases de datos Emerald, Scopus y ScienceDirect, sin marco temporal. Resultados: En 2009 comenzaron a publicarse artículos relacionados con los temas de intercambio de conocimiento e incubadoras de empresas de base tecnológica, con una tímida tendencia de crecimiento en los años siguientes. De acuerdo con la constatación de que se trata de un área aún incipiente en cuanto a publicaciones científicas, los artículos encontrados no cuentan con un elevado número de citas. No fue posible destacar las revistas con mayor número de publicaciones sobre el tema investigado. Las palabras clave encontradas muestran adherencia a las utilizadas en búsquedas en bases de datos. Conclusiones: Con base en el objetivo general de este estudio, este artículo destaca el estado del arte de los temas relacionados. Se seleccionaron nueve estudios para componer el portafolio bibliográfico. El análisis del contenido del portafolio encontrado se presenta como sugerencia para un estudio futuro.
\end{abstract}

Descriptores: Gestión el conocimiento. Intercambio de conocimientos. Análisis Bibiométrico.

Recebido em:14.05.2020

Aceito em: 26.10.2020 